\title{
Mapping quantitative trait loci for disease resistance to false smut of rice
}

\author{
Yanqing Han ${ }^{1,2+}$, Deqiang $\mathrm{Li}^{3 \dagger}$, Jun Yang ${ }^{2}$, Fu Huang ${ }^{3}$, Hongyan Sheng ${ }^{4}$ and Wenxian Sun ${ }^{2,5^{*}}$ (D)
}

\begin{abstract}
False smut of rice, an important emerging disease caused by Ustilaginoidea virens, greatly reduces grain yield and deteriorates grain quality in many rice-growing regions worldwide. Identification of quantitative trait loci (QTL) conferring false smut resistance will facilitate incorporation of false smut resistance into elite cultivars. In this study, a set of recombinant inbred lines (RILs) derived from a cross of a resistant rice landrace MR183-2 and a high susceptible line 08R2394 were evaluated to map resistance QTLs for false smut. A total of 179 simple sequence repeat (SSR) polymorphic markers were identified for constructing genetic linkage maps. Using a composite interval mapping method, five false smut resistance QTLs were detected on chromosomes 2, 4, 8 and 11 in the RIL population. Among these QTLS, GFsr8-1 within a small region on chromosome 8 represents a major quantitative locus explaining the greatest phenotypic variance. Gene annotation in this major QTL region provides a theoretical basis for cloning of resistance QTLs. The SSR markers genetically linked to qFsr8-1 are valuable for marker-assisted breeding for false smut resistance in rice. In addition, nine QTLs for heading date were detected in this population. Correlation analysis of disease resistance score and heading date indicates that false smut resistance negatively correlates with the growth period length in rice.
\end{abstract}

Keywords: Rice false smut, Quantitative trait loci, Ustilaginoidea virens, Gene mapping, Disease resistance gene

\section{Background}

False smut of rice, which was previously considered a minor disease due to its sporadic occurrence (Cooke 1878), has become one of the most destructive diseases in major rice-growing countries (Fan et al. 2015; Sun et al. 2020). The disease has expanded rapidly worldwide, particularly in China and in South Asia, probably because of large-scale planting of high-yield rice varieties and overuse of nitrogenous fertilizers in the past decades (Deng 1989; Zhou et al. 2008). In epidemic years, false smut occurs in about one third of rice cultivation area in China (Jiang et al. 2010; Guo et al. 2012). The causal agent of the disease is the ascomycetous fungus

\footnotetext{
* Correspondence: wxs@cau.edu.cn

†Yanqing Han and Deqiang Li contributed equally to this work.

${ }^{2}$ Department of Plant Pathology and Key Laboratory for Plant Pathology,

Ministry of Agriculture, China Agricultural University, Beijing 100193, China

${ }^{5}$ College of Plant Protection, Jilin Agricultural University, Changchun 130118 ,

China

Full list of author information is available at the end of the article
}

Ustilaginoidea virens (Cooke) Takah (Teleomorph: Villosiclava virens) that is closely related to Claviceps purpurea, a ubiquitous pathogen of cereals and grasses (Tudzynski and Scheffer 2004; Zhang et al. 2014). After $U$. virens infection at the late booting stage, rice spikelets are usually transformed into false smut balls covered with powdery, dark-green chlamydospores after heading. The disease not only causes a significant yield loss (Yang et al. 2012), but also reduces grain quality by generating a variety of mycotoxins, such as ustiloxins and ustilaginoidins, which are toxic to both humans and animals (Lai et al. 2019; Li et al. 2019a).

Because of economic importance, the disease has been extensively studied in different aspects including disease occurrence, pathogen detection, mycotoxin isolation and identification, infection process, resistance evaluation of germplasms, and disease control in recent years (Tang et al. 2013; Wang et al. 2019; Sun et al. 2020). Rapid detection and quantification of $U$. virens from soils and seeds provide practicable techniques for predicting

(c) The Author(s). 2020 Open Access This article is licensed under a Creative Commons Attribution 4.0 International License, which permits use, sharing, adaptation, distribution and reproduction in any medium or format, as long as you give

appropriate credit to the original author(s) and the source, provide a link to the Creative Commons licence, and indicate if changes were made. The images or other third party material in this article are included in the article's Creative Commons licence, unless indicated otherwise in a credit line to the material. If material is not included in the article's Creative Commons licence and your intended use is not permitted by statutory regulation or exceeds the permitted use, you will need to obtain permission directly from the copyright holder. To view a copy of this licence, visit http://creativecommons.org/licenses/by/4.0/ 
epidemic risks and assessing $U$. virens distribution in the fields (Chen et al. 2014; Yang et al. 2018). The infection processes of $U$. virens have also been gradually illustrated (Tang et al. 2013; $\mathrm{Hu}$ et al. 2014; Song et al. 2016). U. virens initially infects rice florets through stamen filaments and thus prevents the production of mature pollen grains and pollination. The pathogen subsequently invades the stigmas and styles, occasionally the ovaries (Tang et al. 2013; Song et al. 2016; Fan et al. 2020). Interestingly, the pathogen might hijack rice nutrient supply system to benefit the formation of false smut balls by simulating ovule fertilization (Fan et al. 2015; Song et al. 2016). Furthermore, $U$. virens genome and the predicted protein-protein interaction network greatly accelerate progress in identifying pathogenicity factors and understanding effector biology in this pathogen (Zhang et al. 2017; Fan et al. 2019; Fang et al. 2019; Sun et al. 2020; Zhang et al. 2020).

At present, disease management strategies for rice false smut include chemical control, cultivation practices, and host resistance. Although fungicide application at the most critical time of $U$. virens infection was effective to control the disease, the optimal timing of spraying fungicides is difficult to be predicted before symptoms appear. Besides, the pathogen has gradually become resistant to some fungicides (Bagga and Kaur 2006). Misuse of fungicides might also cause environmental pollution and ecological imbalance. Cultivation practices, such as furrow irrigation, may provide the immediate and cost-effective remedy for false smut, whereas furrow irrigation may cause other problems that overshadow the benefits of false smut control (Brooks et al. 2010).

Host genetic resistance has been recognized as one of the most economical, environmentally safe and effective strategies for disease control. To date, no rice variety has yet been identified to have complete resistance to $U$. virens, while many cultivars exhibit considerable differences in quantitative field resistance to the pathogen ( $\mathrm{Li}$ et al. 2008; Li et al. 2014; Zhou et al. 2014; Huang et al. 2016). False smut resistance in several rice cultivars has been identified as a quantitative trait controlled by multiple genes (Xu et al. 2002; Li et al. 2011; Andargie et al. 2018). Using near-isogenic introgression lines of "Lemont/Teqing", two quantitative trait loci (QTL) for false smut resistance ( $q F s r 10$ and $q F s r 12)$ were detected in Lemont (Xu et al. 2002). After two-year investigation of disease indices in two sites, ten QTLs affecting percentages of diseased hills, panicles, and spikelets have been further identified using the same set of introgression lines (Zhou et al. 2014). The cultivar IR28 has been identified to have a high field resistance. Using the recombinant inbred lines (RILs) between IR28 and a susceptible landrace Daguandao, seven QTLs controlling false smut resistance were detected ( $\mathrm{Li}$ et al. 2008). In another study (Andargie et al. 2018), resistance QTLs in IR28 were mapped to chromosome 5 by bulk segregate analysis using an $F_{2}$ population derived from its hybrid with a highly susceptible cultivar HXZ. Taken together, a number of QTLs for false smut resistance have been identified. However, QTL mapping of false smut resistance has been performed in only a few parental cultivars. Pyramiding multiple resistance QTLs is considered to be an effective strategy to improve quantitative resistance to plant diseases (Fukuoka et al. 2015). Therefore, it is an urgent need to screen more resistant germplasms and to map false smut resistance QTLs from additional varieties.

In this study, a rice landrace MR183-2 from Sichuan Province was identified to be resistant to false smut. The RILs derived from the hybrid of MR183-2 and a susceptible line 08R2394 were developed for mapping false smut resistance QTLs. Five QTLs for false smut resistance were identified in MR183-2. Molecular markers tightly linked to these QTLs will facilitate markerassisted selection in breeding for false smut resistance.

\section{Results}

A positive correlation between false smut disease severity and heading date in RIL population

Rice plants were grown in disease nurseries with moderate fertilization, regular irrigation and pest management but no disease control. The parental lines and their hybrid descendants were evaluated for false smut disease severity approximately 3 weeks after heading. Thirty parental plants were scored for disease severity at the experimental fields in 2010, 2013 and 2014, respectively. False smut resistance phenotypes were dramatically different between two parental cultivars under natural infection in the false smut disease nursery at Ya'an (Fig. 1). According to the evaluation criteria of false smut resistance (Additional file 1: Table S1), MR183-2 exhibited a high resistance to false smut in 2010 and a moderate resistance in 2013 and 2014, with the percentages of diseased panicles (PDP) of $0.51 \pm 0.07 \%, 6.63 \pm 0.13 \%$ and $6.02 \pm 0.21 \%$, respectively. The parental line $08 \mathrm{R} 2394$ was highly susceptible to the disease in all 3 years with the average PDPs of $34.87 \pm 0.46 \%, 41.55 \pm 0.62 \%$ and $39.96 \pm 0.84 \%$. The resistant cultivar Yixiangyou 2115 and the susceptible cultivar Pujiang6 were used here as positive and negative controls with the PDPs of $2.22 \pm 0.39$ and $36.40 \pm 1.03$, respectively (Table 1 ). Interestingly, the hybrids of MR183-2 and 08R2394 were highly susceptible to false smut, indicating that false smut resistance in MR183-2 is recessive (Table 1 and Additional file 1: Table S1). Meanwhile, 200 RIL- $F_{7}$ lines were observed for false smut disease symptoms in 2014. The PDP and the highest number of diseased grains (HDG) on rice panicles were counted. The coefficient of variation of 


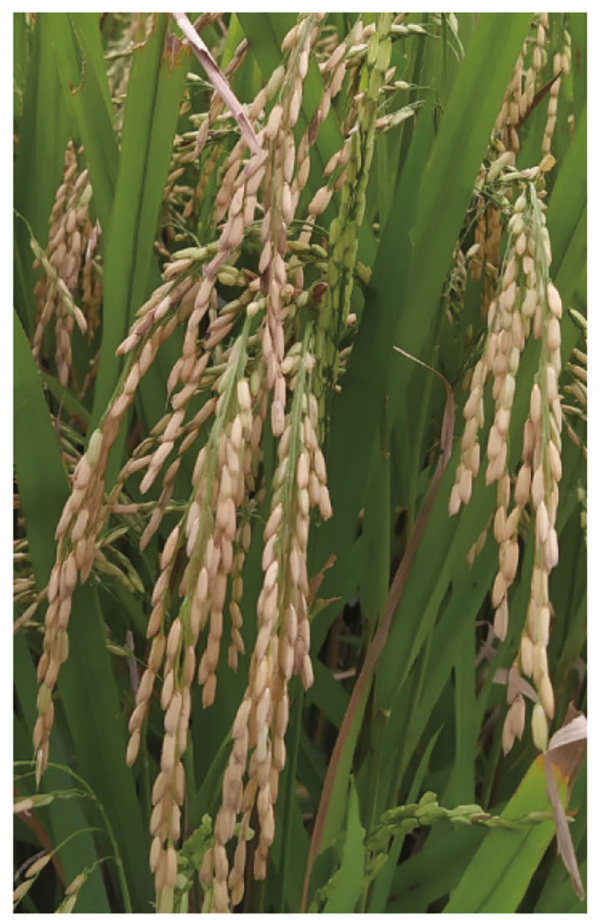

MR183-2

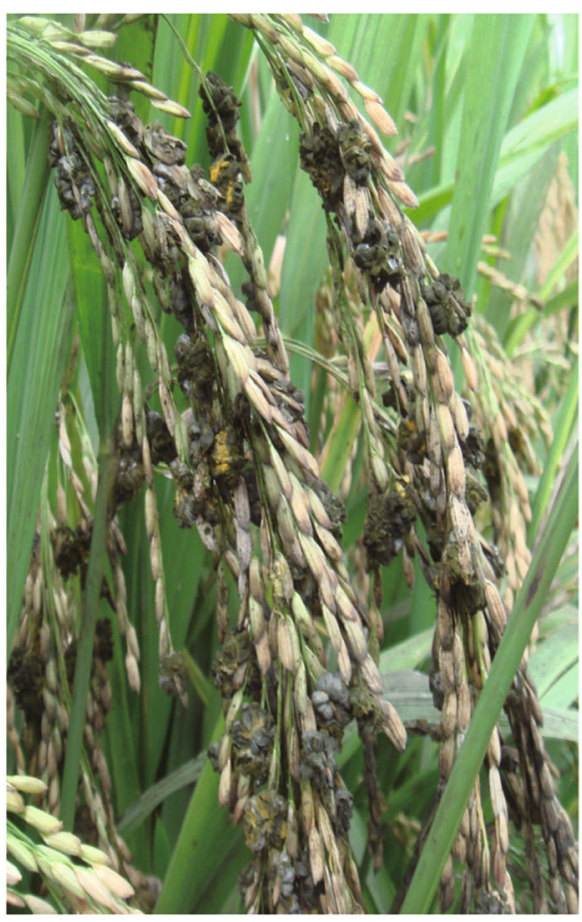

08R2394

Fig. 1 False smut disease phenotypes of rice parental lines $08 R 2394$ and MR183-2. Disease symptoms of false smut on rice panicles of the parental lines 08R2394 and MR183-2 after natural infection. Many false smut balls were formed on rice panicles of 08R2394, whereas only a few balls were formed on MR183-2 panicles. The photos were taken about 4 weeks after heading

PDP was $89.47 \%$, indicating a wide range of variation (Table 2). The false smut resistance scores of RIL- $F_{7}$ lines were categorized based on the PDP and HDG (Fig. 2 and Additional file 1: Table S1). The absolute value of the skewness and kurtosis of resistance scores was less than 1 , indicating an approximately normal distribution of resistance levels of RIL population (Table 2 and Fig. 2). Interestingly, the transgressive phenotype in false smut resistance was observed in some $\mathrm{F}_{7}$ lines (Fig.
2). The results indicate that false smut resistance in MR183-2 is under polygenic control and that the RIL$\mathrm{F}_{7}$ population is suitable for genetic analysis. The heading dates (HD) of parental cultivars and RILs were also recorded. A significant and positive correlation was detected between false smut resistance scores and heading dates $(\mathrm{r}=0.47, P<0.001)$ (Fig. 2). The results suggest that false smut resistance is negatively correlated with the growth period length of rice.

Table 1 False smut disease phenotypes of MR183-2 and 08R2394 after natural infection in a disease nursery in Ya'an, Sichuan Province, China in different years

\begin{tabular}{|c|c|c|c|c|c|c|c|c|c|}
\hline Years & Lines & $\begin{array}{l}\text { Total number of } \\
\text { plants }\end{array}$ & $\begin{array}{l}\text { Total } \\
\text { panicles }\end{array}$ & $\begin{array}{l}\text { Number of diseased } \\
\text { panicles }\end{array}$ & PDP & HDG & $\begin{array}{l}\text { Resistance } \\
\text { score }\end{array}$ & $\begin{array}{l}\text { Resistance } \\
\text { level }\end{array}$ & $P$ value \\
\hline 2010 & Yixiangyou2115 & 30 & 315 & 7 & $2.22 \pm 0.39$ & $<5$ & 1 & $H R$ & - \\
\hline 2010 & Pujiang6 & 30 & 239 & 87 & $36.40 \pm 1.03$ & - & 9 & $\mathrm{HS}$ & - \\
\hline \multirow[t]{2}{*}{2010} & MR183-2 & 30 & 543 & 3 & $0.51 \pm 0.07$ & $<5$ & 1 & $H R$ & \multirow{2}{*}{$\begin{array}{l}1.38 \mathrm{E}- \\
09\end{array}$} \\
\hline & 08R2394 & 30 & 232 & 81 & $34.87 \pm 0.46$ & - & 9 & $\mathrm{HS}$ & \\
\hline 2010 & $\mathrm{~F}_{1}$ & 10 & 110 & 38 & $34.55 \pm 0.68$ & - & 9 & $\mathrm{HS}$ & - \\
\hline \multirow[t]{2}{*}{2013} & MR183-2 & 30 & 422 & 29 & $6.63 \pm 0.13$ & $<7$ & 3 & MR & \multirow{2}{*}{$\begin{array}{l}9.44 \mathrm{E}- \\
09\end{array}$} \\
\hline & 08R2394 & 30 & 407 & 171 & $41.55 \pm 0.62$ & - & 9 & $\mathrm{HS}$ & \\
\hline \multirow[t]{2}{*}{2014} & MR183-2 & 30 & 295 & 18 & $6.02 \pm 0.21$ & $<7$ & 3 & MR & \multirow{2}{*}{$\begin{array}{l}5.19 \mathrm{E}- \\
09\end{array}$} \\
\hline & 08R2394 & 30 & 388 & 153 & $39.96 \pm 0.84$ & - & 9 & $\mathrm{HS}$ & \\
\hline
\end{tabular}


Table 2 Variations in disease phenotype and heading date of parental lines and the RIL-F lines

\begin{tabular}{|c|c|c|c|c|c|c|c|c|}
\hline \multirow[t]{2}{*}{ Traits } & \multicolumn{2}{|c|}{ Parental lines } & \multicolumn{6}{|c|}{ RIL-F $F_{7}$ population } \\
\hline & MR183-2 & 08R2394 & Mean & SD & $\mathrm{CV} \%$ & Kur & Ske & Range \\
\hline PDP & $6.02 \pm 0.21$ & $39.96 \pm 0.84$ & 7.17 & 8.01 & 89.47 & 3.65 & 1.74 & $0-43.08$ \\
\hline RS & 3 & 9 & 4 & 2.56 & 0.64 & -0.83 & 0.11 & $0-9$ \\
\hline $\mathrm{HD}$ & 119 & 117 & 104 & 9.09 & 8.74 & -0.17 & 0.44 & $81-126$ \\
\hline
\end{tabular}

SD, standard deviation; CV, coefficient of variation; Kur, kurtosis; Ske, skewness; PDP, the percentage of diseased panicles; RS, resistance score; HD, heading date

\section{Construction of genetic map and QTL analysis}

In order to map false smut resistance QTLs in MR183-2, genetic linkage maps were constructed based on the genotypes of 200 RIL-F 7 lines. Among 4200 SSR markers, 194 were identified to be polymorphic between resistant and susceptible parents. Among them, 15 polymorphic SSR markers with unclear bands were removed and the remaining 179 markers were integrated into the genetic map consisting of 12 linkage groups. The average genetic distance between two markers on the map was $9.33 \mathrm{cM}$. The order of molecular markers in the linkage maps was generally consistent with that on the published map with only a few exceptions (Temnykh et al. 2000; Mccouch et al. 2002) (Fig. 3).
By composite interval mapping with the software WinQTLCart2.5, five QTLs, qFsr2-1, qFsr4-1, qFsr8-1, $q F s r 8-2$ and $q$ Fsr11-1, were identified on chromosomes $2,4,8,8$ and 11 , explaining $6.9,1.8,26.0,4.0$ and $1.3 \%$ of phenotypic variation, respectively (Table 3, Fig. 3 and Fig. 4). The QTLs $q F s r 4-1, q F s r 8-1$ and $q F s r 11-1$ all showed negative additive effects, indicating that these QTLs are derived from the resistant parent MR183-2 and confers an increased resistance against $U$. virens (Table 3). By contrast, the QTLs qFsr2-1 and qFsr82 exhibited positive additive effects (Table 3) and might be derived from the susceptible line 08R2394. The QTL qFsr8-1 flanked by RM22507 and RM22540 had the largest effect on resistance to false smut explaining $26.0 \%$ of the phenotypic variance,

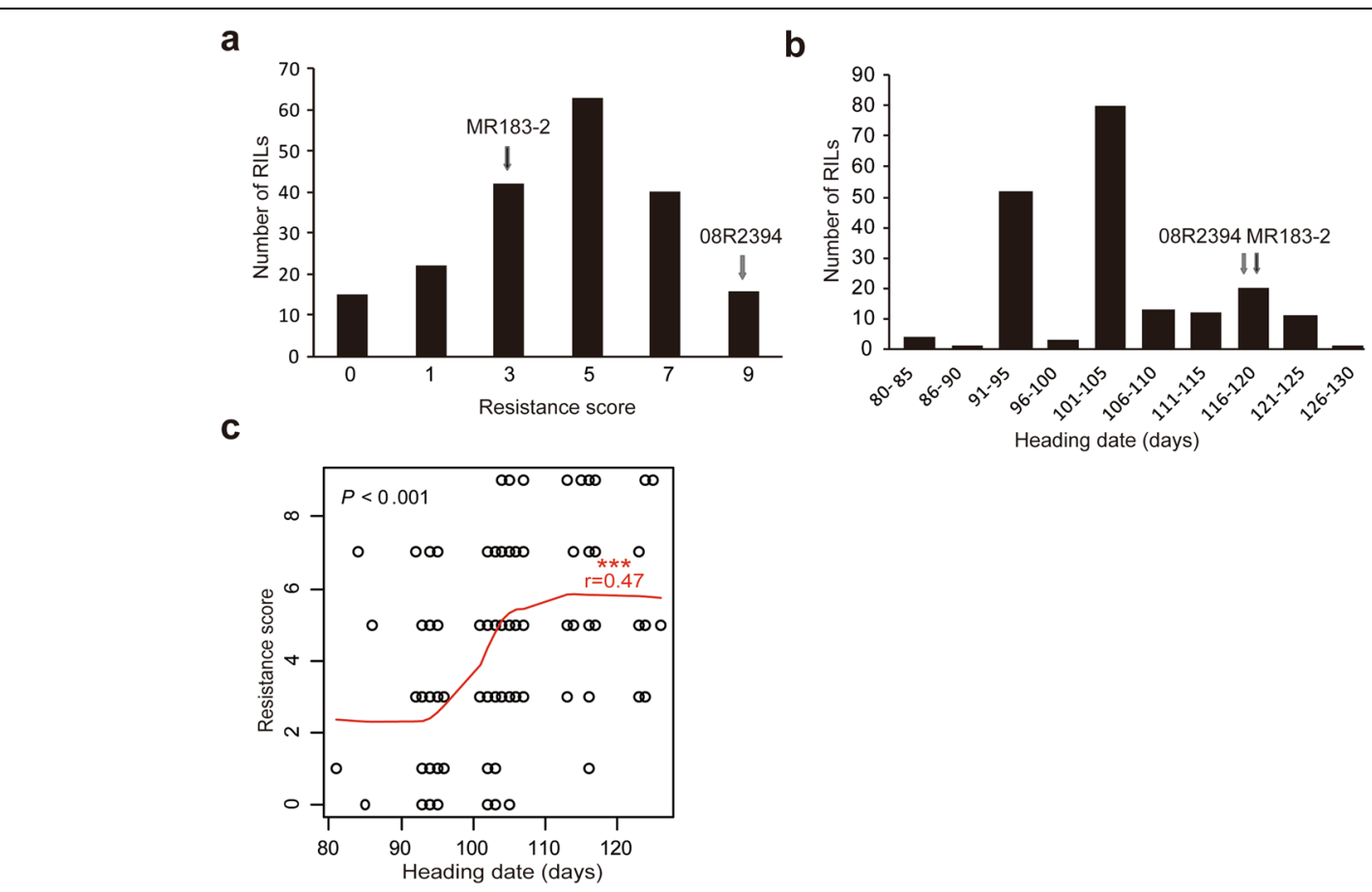

Fig. 2 Distribution of the resistance scores after natural infection, heading dates and phenotypic correlation between them in a RIL-F> population derived from the hybrid of MR183-2 and 08R2394. a Frequency distribution of 200 RILs for false smut resistance scores. Arrows indicate values of the parental lines. $\mathbf{b}$ Frequency distribution of 200 RILs for heading dates. c A significant positive correlation between false smut resistance score and heading date $(r=0.47)$ was found in the RIL population by SPSS 20.0 software. ${ }^{* * *}$ represents a significant difference at $P<0.001$ 


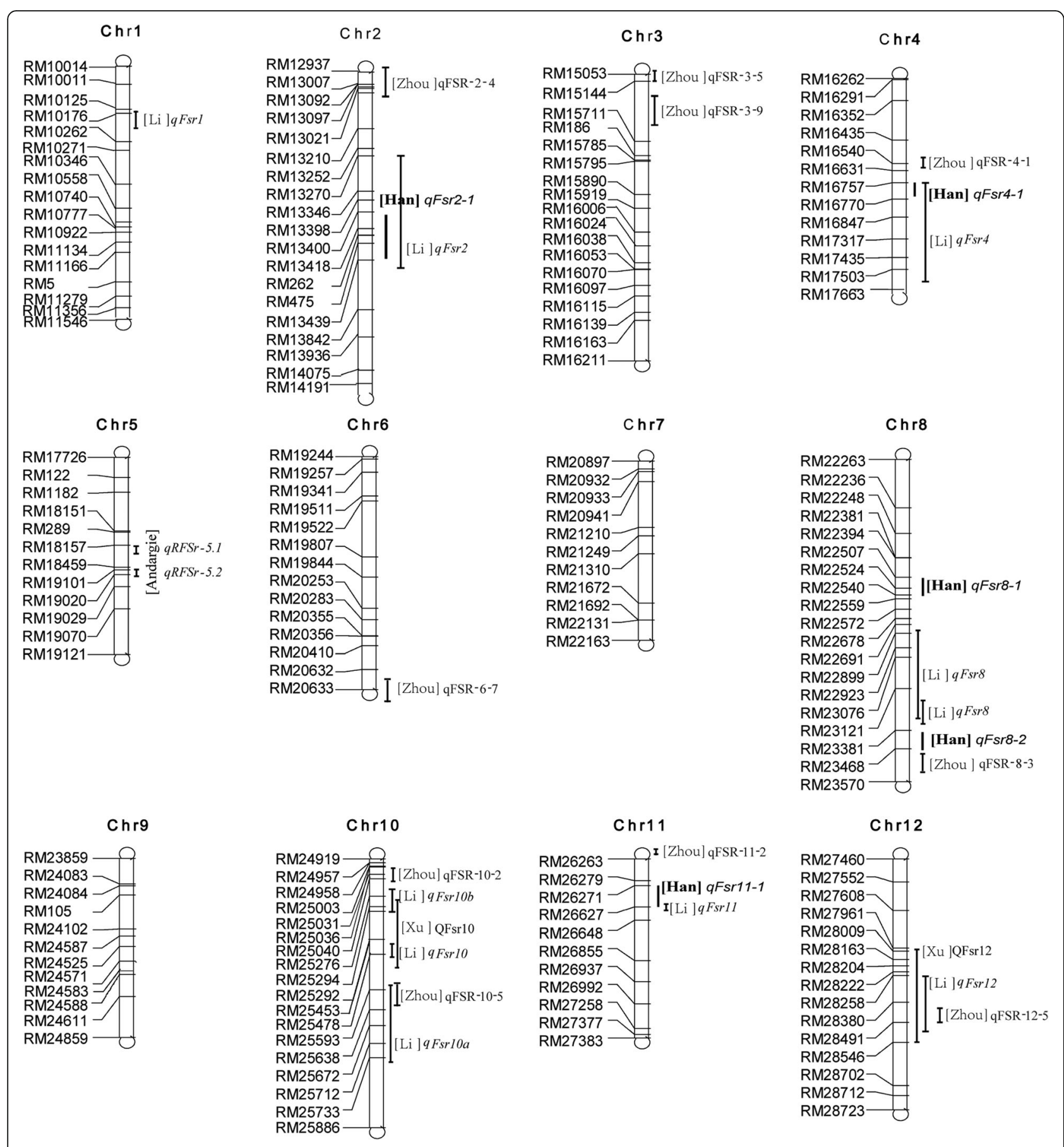

Fig. 3 Construction of genetic map and comparisons of genome locations of QTLs for false smut resistance identified in this and previous studies

indicating that the two markers could be used for marker-assisted selection of false smut resistance derived from MR183-2.

Besides, nine QTLs affecting heading date were identified on chromosomes 1, 2, 3, 8, 9, 11 and 12 (Additional file 2: Table S2). Two of the heading date QTLs (qHd8-1 and $q H d 11-1)$ were overlapped or close to
QTLs for resistance to $U$. virens (Table 3 and Additional file 2: Table S2).

Gene annotation in the major QTL region for false smut resistance

The major QTL $q F s r 8-1$ was mapped in a $\sim 524 \mathrm{~kb}$ region between the SSR markers RM22507 and RM22540. 
Table 3 Quantitative trait loci controlling false smut resistance identified in the RIL-F> population

\begin{tabular}{llllll}
\hline QTL & Chromosome & Interval & LOD & Variance explained (\%) & Additive effect \\
\hline qFsr2-1 & 2 & RM13400-RM13439 & 6.21 & 6.9 & 0.79 \\
qFsr4-1 & 4 & RM16757-RM16770 & 2.69 & 1.8 & -0.28 \\
qFsr8-1 & 8 & RM22507-RM22540 & 15.40 & 26.0 & -1.39 \\
qFsr8-2 & 8 & RM23381-RM23468 & 3.26 & 4.0 & 0.63 \\
qFsr11-1 & 11 & RM26271-RM26627 & 2.67 & 1.3 & -0.13 \\
\hline
\end{tabular}

Since the resistance QTL is much closer to RM22507, the genes within the interval and in the $500 \mathrm{~kb}$ flanking region of RM22507 were searched and annotated. According to gene database from China Rice Data Center (http://www. ricedata.cn/gene/) and rice genome annotation (http:// rice.plantbiology.msu.edu/), 145 genes are located in this region. Among them, the genes LOC_OsO8g07740 (similar to heading date 5, Ghd8) and LOC_Os08g07760 (rice resistance to Xanthomonas oryzae pv. oryzae) have been isolated and reported (Dai et al. 2012; Liao et al. 2016). The other three genes, LOC_Os08g07774, LOC_Os08g07920 and LOC_Os08g07940 were also putative candidate genes involved in disease resistance (Table 4).

\section{Discussion}

It is urgent to develop efficient management strategies to control rice false smut because of severe epidemics and economic importance of the disease (Sun et al. 2020). Screening of false smut resistant cultivars and identification of genes/QTLs for false smut resistance facilitate controlling this devastating disease. In this study, we demonstrated that a rice landrace MR183-2 was resistant to $U$. virens infection. Multiple false smut resistance QTLs were subsequently identified on different chromosomes in rice. The SSR markers tightly linked to these QTLs are valuable for pyramiding false smut resistance into the elite cultivars.

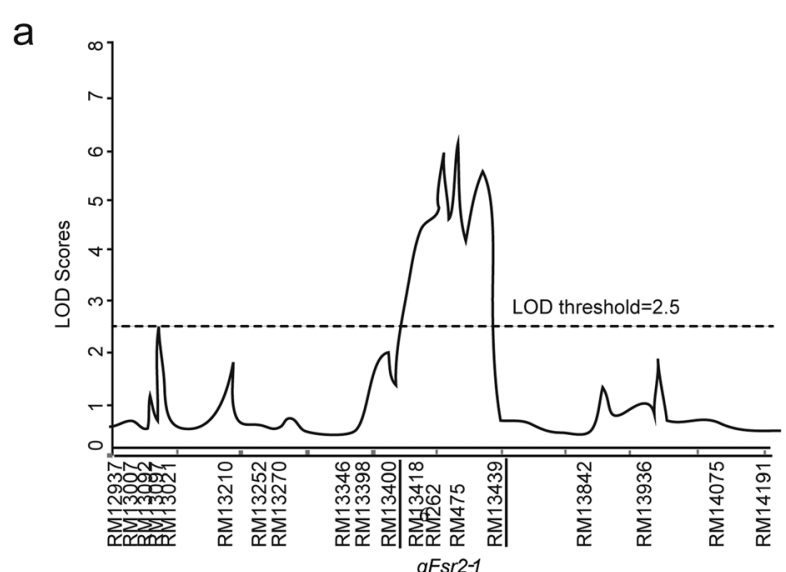

C

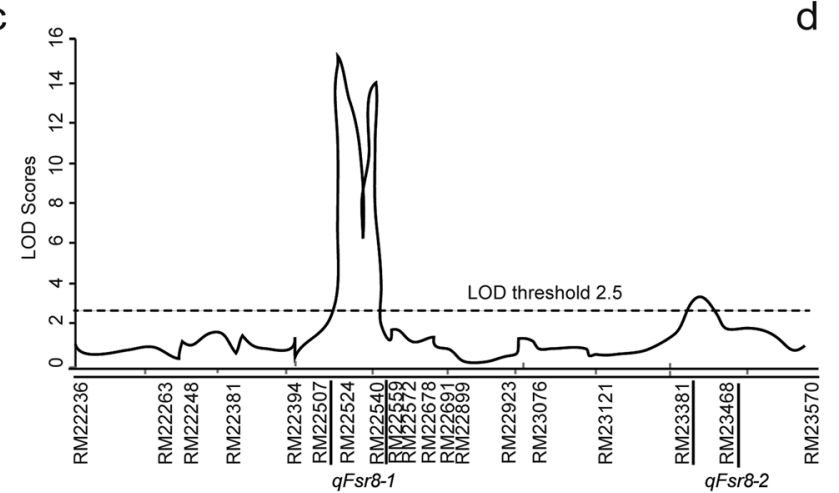

b

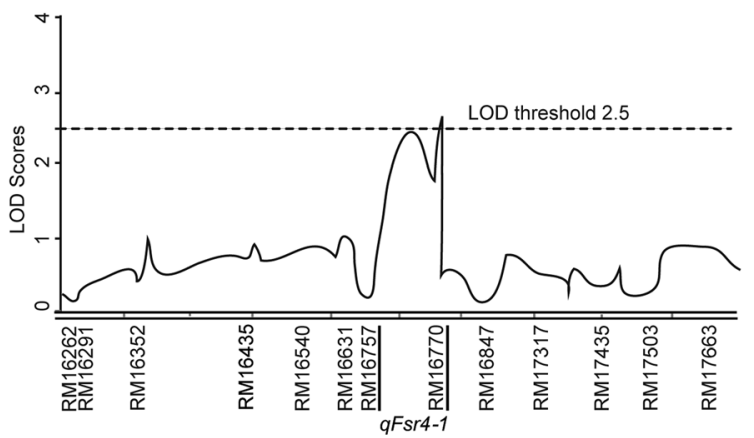

d

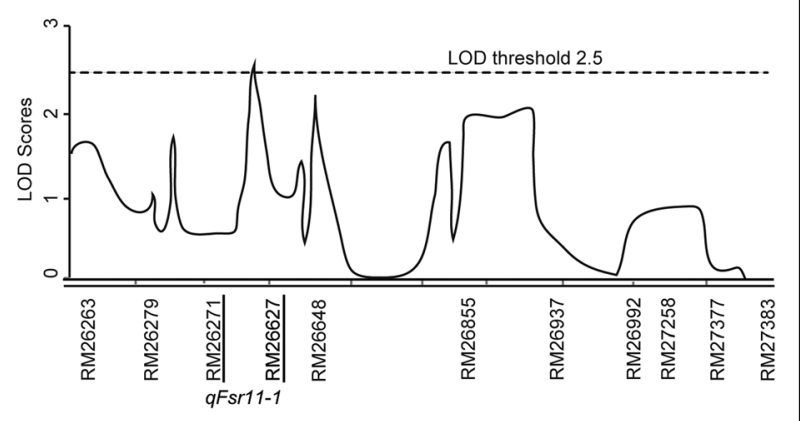

Fig. 4 Five QTLs were identified on chromosomes 2 (a), 4 (b), 8 (c) and 11 (d) using the F population derived from a hybrid of MR183-2 and 08R2392. The dotted lines showed a threshold value of LOD (LOD > 2.5) 
Table 4 The candidate genes that might be involved in disease resistance at the major QTL region of aFsr8-1

\begin{tabular}{ll}
\hline Gene loci & Annotation information \\
\hline LOC_Os08g07740 & Similar to heading date 5, Ghd8 \\
LOC_Os08g07760 & Rice resistance to PXO99, OsBAK1 \\
LOC_Os08g07774 & Disease resistance protein RPM1, putative, expressed \\
LOC_Os08g07920 & Disease resistance protein RPM1, putative, expressed \\
LOC_Os08g07940 & Disease resistance protein RPM1, putative, expressed \\
\hline
\end{tabular}

Simple sequence repeats (SSR) are universally distributed in plant genomes and are often used as molecular markers in the genetic linkage analysis and QTL mapping (Chen et al. 2017; Su et al. 2018; Rahman et al. 2019). In this study, a low percentage $(<5 \%)$ of SSR markers were identified to be polymorphic between the parental cultivars, which might be caused by high genetic similarity between 08R2394 and MR183-2, which are both Indica rice lines. Many fewer polymorphic SSR markers have been identified between two Indica restorer lines T219 and T226 compared with those between Indica and Japonica varieties (Chen and Zhang 2009). The closer genetic relationship between the varieties was correlated with a lower rate of SSR polymorphism (Zhang et al. 2005). In addition, relatively low polymorphism of SSR markers may be also due to the limitation of the detection method. Compared with polyacrylamide gel, agarose gel has a much lower sensitivity to detect SSR marker polymorphism.

To date, 24 false smut resistance QTLs have been mapped to all of rice chromosomes but chromosomes 7 and 9 in a few rice cultivars, although some of the identified QTLs are located at the same or overlapping chromosome regions (Fig. 3). Based on the constructed genetic linkage maps and resistance phenotypes, five QTLs were mapped to the chromosomes 2, 4, 8, and 11 in this study (Table 3, Fig. 3 and Fig.4). The qFsr2-1 locus is located within the interval of the previously identified locus $q F s r 2$, while $q F s r 4-1$ and $q F s r 11-1$ partially overlaps with the previously identified $q F s r 4$ and qFsr11 using Daguandao/IR28 recombinant inbred lines (Fig. 3) (Li et al. 2008, 2011, 2014; Zhou et al. 2014). Interestingly, the QTL $q F s r 8-1$ is a novel resistance locus that has not been reported previously. More importantly, $q F s r 8-1$ explained the greatest phenotypic variance among all of false smut resistance QTLs identified in this and previous studies. Another major quantitative locus qFsr1 from IR28 explained $22.5 \%$ of phenotypic variance ( $\mathrm{Li}$ et al. 2014). Therefore, it is promising to pyramid these major resistance QTLs into an elite cultivar to improve false smut resistance. According to gene prediction and annotation in the region of the major QTL $q F s r 8-1$, several genes were predicted to be involved in disease resistance. For instance, the gene LOC_Os08g07760 has been identified to confer resistance to bacterial blight in rice (Liao et al. 2016). In addition, LOC_Os08g07774, LOC_Os08g07920 and LOC_Os08g07940 encode the RPM1 type of resistance proteins, which are involved in disease resistance in multiple plant species (Grant et al. 1995; Nie and Ji 2019; Li et al. 2019b). Therefore, it is interesting to investigate whether these genes play important roles in the regulation of false smut resistance.

Interestingly, a significant positive correlation between false smut resistance score and heading date was revealed in this RIL population (Fig. 2). It has been previously reported that disease resistance is sometimes associated with agronomic traits in crop plants (Yan et al. 2011; Dai et al. 2012). A negative correlation between Fusarium head blight severity and heading date has been reported in wheat (Paillard et al. 2004; Schmolke et al. 2005). In contrast, multiple rice lines in the RIL population with earlier heading dates exhibited enhanced resistance to $U$. virens, indicating that the line with a shorter growth period length tends to show less false smut infection. The possible reason for this correlation includes that the anthesis of rice lines with earlier heading dates evades from the critical infection period of $U$. virens. In the genetic level, the genes controlling false smut resistance and early heading are either tightly linked or the same gene with pleiotropic effects. Consistently, $q H d 8-1$ for heading date is mapped to the identical region of $q F s r 8-1$ controlling false smut resistance. Interestingly, Ghd8, which plays pleiotropic roles in regulating grain productivity, plant height and heading date in rice, is located in the region (Table 4). Therefore, we speculate that $q H d 8-1$, probably Ghd8, may also regulate false smut resistance or instead it is tightly linked with false smut resistance gene. This finding suggests an effective strategy to rice breeding for false smut resistance by focusing on the lines with shorter growth period.

In this study, false smut resistance in some individual lines in RIL- $F_{7}$ population was higher than that of the parental lines, indicating a phenomenon of transgressive segregation (Fig. 2). Transgressive segregation produces hybrid progeny phenotypes exceeding the parental phenotypes, which widely exists in plant species (Grandillo and Tanksley 1996; Koide et al. 2019). The QTLs for false smut resistance were identified in both false smut resistant and susceptible parental lines (Table 3). Therefore, transgressive phenotypes might be produced by the cumulative effect of resistant QTLs from both parental lines, which provides the basis for pyramiding resistance QTLs. It is worthwhile to note that false smut resistance in the cultivar MR183-2 is most probably recessive, which make it difficult to pyramid resistance QTLs into elite cultivars. However, newly-developed gene editing 
technologies can be exploited to modify the susceptible genes in molecular design breeding for disease resistance (Jiang et al. 2013).

An accurate and highly efficient approach to evaluate false smut resistance is extremely important for QTL mapping. An artificial inoculation method has been developed for false smut resistance evaluation by injecting the mixture of $U$. virens conidiospores and smashing hyphae into rice panicles at the late booting stage (Fujita et al. 1989; Ashizawa et al. 2012; Hu et al. 2014). This method has been proven to be successful in accurate evaluation of disease incidence on rice panicles under stringently controlled environmental conditions ( $\mathrm{Hu}$ et al. 2014). However, the method is not suitable for testing large mapping populations because it is time-consuming and requires wellequipped facilities for disease development. Alternatively, we evaluated the resistance phenotypes of mapping populations at disease nurseries, which have been under disease-inducing conditions in multiple years. Natural infection has been performed in most of breeding programs and selection for false smut resistance (Zhou et al. 2014; Jiang et al. 2015). Some false smut disease phenotypes, such as PDP, can be only assessed under natural infection. Multiple QTLs associated with resistance to false smut were detected in introgression lines from a cross between Teqing and Lemont using natural infection. In addition, other agronomic traits, such as heading date, can be simultaneously investigated to identify multiple complicate phenotypes. The QTLs detected under natural infection may confer broad-spectrum and durable resistance, which has profound practical implications for rice breeding programs ( $\mathrm{Li}$ et al. 2008). Although natural infection has some advantages in QTL analysis for plant disease resistance over artificial inoculation ( $\mathrm{Li}$ et al. 2008), natural infection of $U$. virens is greatly influenced by environmental conditions, such as temperature and moisture. Therefore, the disease resistance phenotypes under natural infection need to be evaluated at multiple sites and in different years for accuracy.

\section{Conclusions}

In summary, five QTLs for false smut resistance have been identified in this study. Particularly, $q F s r 8-1$ is a novel and valuable locus that has a major effect on false smut resistance. Some candidate genes involved in disease resistance were predicted in this major QTL region. The qFsr8-1-linked SSR markers are being used for marker-assisted selection in breeding cultivars with false smut resistance. Interestingly, the major QTLs controlling false smut resistance and heading date in rice are mapped in the identical region and are probably tightly linked. The findings provide important information for fine mapping and isolating the genetic loci controlling false smut resistance and for developing rice cultivars with false smut resistance.

\section{Methods}

\section{Plant materials}

MR183-2 is an indica type of rice landrace, which is potentially resistant to false smut, while the other parent, 08R2394, is a high-yielding and susceptible indica rice line. A recombinant inbred line (RIL) population composed of $200 \mathrm{~F}_{7}$ lines was developed from a cross of 08R2394 and MR183-2 by the single seed descent method. The rice cultivars Yixiangyou2115 and Pujiang6 were used as false smut resistant and susceptible controls, respectively.

\section{Evaluation of field resistance to $U$. virens}

The parental and control cultivars, $F_{1}$ plants and the RIL population were evaluated for resistance to $U$. virens by natural infection in a disease nursery located at Guanghua village, Daba Town, Ya'an city, Sichuan Province. Rice seeds were sterilized in $0.1 \% \mathrm{C}_{3} \mathrm{~N}_{3} \mathrm{O}_{3} \mathrm{Cl}_{3}$ solution for $24 \mathrm{~h}$ at room temperature before sowing. Thirty-dayold seedlings of each line were transplanted into a 3-row plot with 10 hills per row at a spacing of $30 \mathrm{~cm} \times 20 \mathrm{~cm}$. Three replications were arranged for each line in randomized blocks in the disease nursery.

In order to increase the primary pathogen inoculum in the disease nursery, chlamydospore balls of $U$. virens were collected from the experimental fields in previous years and were uniformly distributed over the disease nursery in the coming years. The PDP per hill and the number of diseased grains on rice panicles in parental lines and their hybrid offspring were recorded when false smut balls were evidently visible on rice panicles.

The PDP was calculated using the following formula: $\mathrm{PDP}=100 \% \times$ the number of diseased panicles/total number of panicles. The disease severity was evaluated according to the PDP and HDG using the criteria as described previously with some minor modifications (Huang et al. 2016). Briefly, in the previous criteria, the HDG of 7 was fixed as the threshold in the different scales. Instead, we adjusted the HDG threshold to 5, 7 and 9 in different scales to evaluate disease resistance scores more precisely (Additional file 1: Table S1). Variation and correlation analyses of the PDP, resistance scores and heading dates were performed using SPSS 20.0 software.

\section{Genotyping}

Genomic DNA was extracted from rice leaves of parental lines and different RIL- $\mathrm{F}_{7}$ lines using the cetyl trimethylammonium bromide (CTAB) method (Murray 
and Thompson 1980). PCRs were performed in a $10 \mu \mathrm{L}$ of reaction volume containing $30 \mathrm{ng}$ template DNA, a pair of SSR primers $(0.2 \mu \mathrm{M}$, each primer), $5 \mu \mathrm{L}$ of $2 \times$ Taq PCR master mix (Biomed, China) using the following programs: $94{ }^{\circ} \mathrm{C}$ for $4 \mathrm{~min}, 35 \times\left(94{ }^{\circ} \mathrm{C}\right.$ for $30 \mathrm{~s}$, $52{ }^{\circ} \mathrm{C}-63^{\circ} \mathrm{C}$ for different SSR primers for $30 \mathrm{~s}, 72{ }^{\circ} \mathrm{C}$ for $30-60 \mathrm{~s}$ ), and $72^{\circ} \mathrm{C}$ for $5 \mathrm{~min}$. PCR products were separated on $3 \%(\mathrm{w} / \mathrm{v})$ agarose gels and were then visualized after ethidium bromide staining using a gel documentation system (AlphaImager HP, Alpha Innotech Corp., USA).

Rice microsatellite (RM) markers used in this study were selected from a rice genetic map constructed by McCouch et al. (2002). The sequences and location information regarding these SSR markers were downloaded from http://www.gramene.org. A total of 4200 SSR markers distributed on all 12 rice chromosomes were synthesized to screen for polymorphic markers between the parental lines 08R2394 and MR183-2, which were used for constructing linkage map. Genotyping was performed for 200 RILs using polymorphic SSR markers.

\section{Linkage map construction and QTL analysis}

The genotyping data were used for linkage map construction by Mapmaker/EXP v3.0 (Lander et al. 1987). A LOD score of 3.0 and a maximal map distance of $50 \mathrm{cM}$ were set to identify linkage groups. The Kosambi mapping function was used to convert recombination frequencies into cM values (Kosambi 1943). The final maps were drawn using the MapChart program (Voorrips 2002).

Resistance to false smut of rice was classified by the scores ranging from 0 to 9 . Based on these resistance scores, QTLs for rice smut resistance were detected in the RIL population using composite interval mapping (CIM) method by the software QTL Cartographer for Windows version 2.5 (WinQTLCart2.5) with a window size of $10.0 \mathrm{cM}$ (Wang et al. 2012). LOD threshold in each experiment was determined by 1000-permutation times $(P<0.05)$. Potential QTLs were identified with a minimum LOD score threshold of 2.5. The phenotypic variation explained by a single QTL was determined by the square of the partial correlation coefficient $\left(R^{2}\right)$.

\section{Gene annotation and prediction}

The genes within the interval of $q F s r 8-1$ and flanking region were predicted and annotated based on gene database from China Rice Data Center (http://www.ricedata.cn/gene/). The putative genes involved in disease resistance were predicted based on rice genome annotation (http://rice.plantbiology.msu.edu/).

\section{Supplementary information}

Supplementary information accompanies this paper at https://doi.org/10. 1186/s42483-020-00059-6.

Additional file 1 Table S1. Evaluation criteria for resistance to false smut of rice

Additional file $\mathbf{2}$ Table S2. Quantitative trait loci for heading date identified in the RIL-F $F_{7}$ population

\section{Abbreviations \\ CV: Coefficient of variation; HD: Heading date; PDP: The percentage of diseased panicles; HDG: The highest number of diseased grains; \\ QTL: Quantitative trait loci; RIL: Recombinant inbred line; RS: Resistance score; \\ SD: Standard deviation; SSR: Simple sequence repeat; \\ CTAB: Cetyltrimethylammonium bromide; RM: Rice microsatellite: \\ CIM: Composite interval mapping}

\section{Acknowledgements}

We are grateful to Dr. Yuan-huai Han at Shanxi Agricultural University, Lu-bin Tan and Zuo-feng Zhu at China Agricultural University, and two anonymous reviewers for useful suggestions and discussion.

\section{Authors' contributions}

WS and FH designed the research; YH, DL and JY performed the research; $\mathrm{YH}$, WS and HS wrote the manuscript. All authors read and approved the

final manuscript.

\section{Funding}

The work is supported by National Natural Science Foundation of China (grants 31630064 and U19A2027) to WS, by Innovation Foundation of Shanxi Agricultural University (2016YJ05) to YH, and by Hundred Talents Program of Shanxi Province and the 111 project D17014.

Availability of data and materials

All data generated or analyzed during this study are included in this published article.

Ethics approval and consent to participate

Not applicable.

Consent for publication

Not applicable.

\section{Competing interests}

The authors declare that they have no competing interests.

\section{Author details}

'College of Plant Protection, Shanxi Agricultural University, Taigu 030801, China. ${ }^{2}$ Department of Plant Pathology and Key Laboratory for Plant Pathology, Ministry of Agriculture, China Agricultural University, Beijing 100193, China. ${ }^{3}$ College of Agronomy, Sichuan Agricultural University, Chengdu 611130, China. ${ }^{4}$ Department of Plant Pathology, Washington State University, Pullman, WA 99164-6430, USA. ${ }^{5}$ College of Plant Protection, Jilin Agricultural University, Changchun 130118, China.

Received: 21 March 2020 Accepted: 2 July 2020

Published online: 30 July 2020

\section{References}

Andargie M, Li L, Feng A, Zhu X, Li J. Mapping of the quantitative trait locus (QTL) conferring resistance to rice false smut disease. Curr Plant Biol. 2018;15: 38-43.

Ashizawa T, Takahashi M, Arai M, Arie T. Rice false smut pathogen, Ustilaginoidea virens, invades through small gap at the apex of a rice spikelet before heading. J Gen Plant Pathol. 2012;78:255-9.

Bagga PS, Kaur S. Evaluation of fungicides for controlling false smut (Ustilaginoidea virens) of rice. Indian Phytopathol. 2006;59(1):115-7.

Brooks SA, Anders MM, Yeater KM. Effect of furrow irrigation on the severity of false smut in susceptible rice varieties. Plant Dis. 2010;94:570-4. 
Chen Q, Song J, Du WP, Xu LY, Jiang Y, Zhang J, et al. Identification, mapping, and molecular marker development for Rgsr8.1: a new quantitative trait locus conferring resistance to Gibberella stalk rot in maize (Zea mays L.). Front Plant Sci. 2017:8:1355.

Chen QQ, Zhang YS. Distorted segregation and construction of molecular linkage map of SSR markers in Indica rice. Mol Plant Breed. 2009;7(4):685-9 (in Chinese). http://en.cnki.com.cn/Article_en/CJFDTOTAL-FZZW200904012.htm.

Chen Y, Yao J, Li YF, Wang WX, Yang X, Zhang AF. Simple and rapid detection of rice false smut pathogen Ustilaginoidea virens in rice seeds. Phytoparasitica. 2014:42:371-5.

Cooke MC. Some extra-European fungi. Grevillea. 1878;7:13-5.

Dai XD, Ding YN, Tan LB, Fu YC, Liu FX, Zhu ZF, et al. LHD1, an allele of DTH8/ Ghd8, controls late heading date in common wild rice (Oryza rufipogon). J Integr Plant Biol. 2012:54(10):790-9.

Deng GS. Present status of research on false smut in China. Plant Prot. 1989;15(6): 39-40 (in Chinese).

Fan J, Du N, Li L, Li GB, Wang YQ, Zhou YF, et al. A core effector UV_1261 promotes Ustilaginoidea virens infection via spatiotemporally suppressing plant defense. Phytopathol Res. 2019;1:11.

Fan J, Guo XY, Li L, Sun WX, Li Y, Huang YY, et al. Infection of Ustilaginoidea virens intercepts rice seed formation but activates grain-filling-related genes. $J$ Integr Plant Biol. 2015;57(6):577-90.

Fan J, Liu J, Gong ZY, Xu PZ, Hu XH. The false smut pathogen Ustilaginoidea virens requires rice stamens for false smut ball formation. Environ Microbiol. 2020;22(2):646-59.

Fang A, Gao H, Zhang N, Zheng X, Qiu S, Li Y, et al. A novel effector gene SCRE2 contributes to full virulence of Ustilaginoidea virens to rice. Front Microbiol. 2019;10:845.

Fujita Y, Sonoda R, Yaegashi H. Inoculation with conidiospores of false smut fungus to rice panicles at the booting stage. Ann Phytopathol Soc Jpn. 1989; 55:629-34 (In Japanese).

Fukuoka S, Saka N, Mizukami Y, Koga H, Yamanouchi U, Yoshioka Y, et al. Gene pyramiding enhances durable blast disease resistance in rice. Sci Rep. 2015;5:7773.

Grandillo S, Tanksley SD. QTL analysis of horticultural traits differentiating the cultivated tomato from the closely related species Lycopersicon pimpinellifolium. Theor Appl Genet. 1996;92(8):935-51.

Grant MR, Godiard L, Straube E, Ashfield T, Lewald J, Sattler A, et al. Structure of the Arabidopsis RPM1 gene enabling dual specificity disease resistance. Science. 1995;269(5225):843-6.

Guo X, Li Y, Fan J, Li L, Huang F, Wang WM. Progress in the study of false smut disease in rice. J Agric Sci Technol A. 2012;2:1211-7.

Hu ML, Luo L, Wang S, Liu Y, Li J. Infection processes of Ustilaginoidea virens during artificial inoculation of rice panicles. Eur J Plant Pathol. 2014;139:67-77.

Huang F, Li Y, Shi J, Fan J, Li DQ, Xu YJ, et al. Screening and polymorphism analysis of rice germplasms for resistance to false smut disease in Sichuan Province. Acta Phytopathol Sin. 2016;46:247-57 (in Chinese). http://zwblxb. magtech.com.cn/CN/abstract/abstract657.shtml.

Jiang H, Yan B, Duan T, Li Y, Gao G, Zhang Q, et al. Mapping and evaluating quantitative trait loci for blast resistance under natural infection conditions using an advanced backcross population in rice. Euphytica. 2015;204:121-33.

Jiang S, Tang CS, Tan ZQ. Advances on studies about false smut of rice. China J Trop Agric. 2010;30:62-6 (in Chinese). http://en.cnki.com.cn/Article_en/ CJFDTOTAL-RDNK201003018.htm.

Jiang WZ, Zhou H, Bi H, Fromm ME, Yang B. Demonstration of CRISPR/Cas9/ sgRNA-mediated targeted gene modification in Arabidopsis, tobacco, sorghum and rice. Nucleic Acids Res. 2013;41(20):e188.

Koide Y, Sakaguchi S, Uchiyama T, Ota Y, Tezuka A, Nagano AJ, et al. Genetic properties responsible for the transgressive segregation of days to heading in rice. G3: Genes Genomes Genet. 2019;9(5):1655-62. https://doi.org/10. 1534/g3.119.201011.

Kosambi DD. The estimation of map distances from recombination values. Ann Eugenics. 1943;12:172-5.

Lai DW, Meng JJ, Zhang XP, Xu D, Dai JG, Zhou LG. Ustilobisorbicillinol a, a cytotoxic sorbyl-containing aromatic polyketide from Ustilaginoidea virens. Org Lett. 2019;21(5):1311-4.

Lander ES, Green P, Abrahamson J, Barlow A, Daly MJ, Lincoln SE, et al. MAPMAK ER: an interactive computer package for constructing primary genetic linkage maps of experimental and natural populations. Genomics. 1987;1:174-81.

Li Y, Wang M, Liu Z, Zhang K, Cui F, Sun W. Towards understanding the biosynthetic pathway for ustilaginoidin mycotoxins in Ustilaginoidea virens. Environ Microbiol. 2019a;21 (8):2629-43.
Li YS, Huang SD, Yang J, Wang CL. Analysis of quantitative trait loci for resistance to rice false smut. Acta Agron Sin. 2011;37(5):778-83 (in Chinese). http:// zwxb.chinacrops.org/CN/10.3724/SP.J.1006.2011.0e0778.

Li YS, Yang J, Huang SD, Wang CL. Analysis on quantitative trait loci for resistance to rice false smut under different environmental conditions. Agric Sci Technol. 2014;15(3):449-52.

Li YS, Zhang YD, Zhu Z, Zhao L, Wang CL. QTL analysis for resistance to rice false smut by using recombinant inbred lines in rice. Chinese J Rice Sci. 2008;22(5): 472-6 (in Chinese). http://www.ricesci.cn/EN/abstract/abstract1700.shtml.

Li ZW, Huang JZ, Wang ZY, Meng F, Zhang SY, Wu XQ, et al. Overexpression of Arabidopsis nucleotide-binding and leucine-rich repeat genes RPS2 and RPM1(D505V) confers broad-spectrum disease resistance in rice. Front Plant Sci. 2019b;10:417.

Liao HL, Xiao XR, Li XQ, Chen Y, Fu XM, Lin DZ, et al. OsBAK1 is involved in rice resistance to Xanthomonas oryzae pv. oryzae PXO99. Plant Biotechnol Rep. 2016;10:75-82.

McCouch SR, Teytelman L, Xu Y, Lobos KB, Clare K, Walton M, et al. Development and mapping of 2240 new SSR markers for rice (Oryza sativa L.) (supplement). DNA Res. 2002;9:257-79.

Murray MG, Thompson WF. Rapid isolation of high molecular weight plant DNA. Nucleic Acids Res. 1980;8:4321-6.

Nie YB, Ji WQ. Cloning and characterization of disease resistance protein RPM1 genes against powdery mildew in wheat line N9134. Cereal Res Commun. 2019;47(3):473-83.

Paillard S, Schnurbusch T, Tiwari R, Messmer M, Winzeler M, Keller B, et al. QTL analysis of resistance to Fusarium head blight in Swiss winter wheat (Triticum aestivum L). Theor Appl Genet. 2004;109:323-32.

Rahman MA, Thomson MJ, De Ocampo M, Egdane JA, Salam MA, Shah-E-Alam $\mathrm{M}$, et al. Assessing trait contribution and mapping novel QTL for salinity tolerance using the Bangladeshi rice landrace capsule. Rice. 2019;12:63.

Schmolke M, Zimmermann G, Buerstmayr H, Schweizer G, Miedaner T, Korzun V, et al. Molecular mapping of Fusarium head blight resistance in the winter wheat population dream/lynx. Theor Appl Genet. 2005;111(4):747-56.

Song J-H, Wei W, Lv B, Lin Y, Yin W-X, Peng Y-L, et al. Rice false smut fungus hijacks the rice nutrients supply by blocking and mimicking the fertilization of rice ovary. Environ Microbiol. 2016;18:3840-9.

Su Q, Zhang X, Zhang W, Zhang N, Song L, Liu L, et al. QTL detection for kerne size and weight in bread wheat (Triticum aestivum L.) using a high-density SNP and SSR-based linkage map. Front Plant Sci. 2018;9:1484.

Sun WX, Fan J, Fang A, Li Y, Tariqjaveed M, Li D, et al. Ustilaginoidea virens: insights into an emerging rice pathogen. Annu Rev Phytopathol. 2020;58. https://doi.org/10.1146/annurev-phyto-010820-012908.

Tang Y-X, Jin J, Hu D-W, Yong M-L, Xu Y, He L-P. Elucidation of the infection process of Ustilaginoidea virens (teleomorph: Villosiclava virens) in rice spikelets. Plant Pathol. 2013;62:1-8.

Temnykh S, Park WD, Ayres N, Cartinhour S, Hauck N, Lipovich L, et al. Mapping and genome organization of microsatellite sequences in rice (Oryza sativa L.). Theor Appl Genet. 2000;100:697-712.

Tudzynski P, Scheffer J. Claviceps purpurea: molecular aspects of a unique pathogenic lifestyle. Mol Plant Pathol. 2004;5(5):377-88.

Voorrips RE. MapChart: software for the graphical presentation of linkage maps and QTL. J Hered. 2002;93:77-8.

Wang S, Basten CJ, Zeng ZB. Windows QTL cartographer 2.5. Raleigh: Department of Statistics, North Carolina State University; 2012. http://statgen. ncsu.edu/atlcart/WQTLCart.htm.

Wang WM, Fan J, Jeyakumar JMJ. Rice false smut: an increasing threat to grain yield and quality. In: Jia Y, editor. Protecting rice grains in the post-genomic era. London: IntechOpen; 2019. p. 89-108.

Xu JL, Xue QZ, Luo L, Li ZK. Preliminary report on quantitative trait loci mapping of false smut resistance using near-isogenic introgression lines in rice. Acta Agric Zhejiangensis. 2002;14(1):14-9 (in Chinese). http://www.zjnyxb.cn/CN/ abstract/abstract449.shtml.

Yan WH, Wang P, Chen HX, Zhou HJ, Li QP, Wang CR, et al. A major QTL, Ghd8, plays pleiotropic roles in regulating grain productivity, plant height, and heading date in rice. Mol Plant. 2011;4(2):319-30.

Yang LM, Chen L, Xu J, Liu JC, Ding KJ. Estimation of yield loss caused by rice false smut. J Anhui Agric Univ. 2012;39(3):474-7 (in Chinese). http://ahnydxxb.ahau. edu.cn/ch/reader/view_abstract.aspx?file_no=201203032\&flag=1.

Yang X, Al-Attala MN, Zhang Y, Zhang AF, Zang HY, Gu CY, et al. Rapid detection of Ustilaginoidea virens from rice using loop-mediated isothermal amplification assay. Plant Dis. 2018;102:1741-7. 
Zhang K, Li Y, Li T, Li ZG, Hsiang T, Zhang Z, et al. Pathogenicity genes in Ustilaginoidea virens revealed by a predicted protein-protein interaction network. J Proteome Res. 2017;16(3):1193-206.

Zhang N, Yang J, Fang A, Wang J, Li D, Li Y, et al. The essential effector SCRE1 in Ustilaginoidea virens suppresses rice immunity via a small peptide region. Mol Plant Pathol. 2020;21 (4):445-59.

Zhang QJ, Ye SP, Yu DR, Li P, Lv CG, Zou JS. Comparison of six rice genetic linkage maps. Southwest China J Agric Sci. 2005;5:584-92 (in Chinese). http:// en.cnki.com.cn/Article_en/CJFDTOTAL-XNYX200505017.htm.

Zhang Y, Zhang K, Fang A, Han Y, Yang J, Xue M, et al. Specific adaptation of Ustilaginoidea virens in occupying host florets revealed by comparative and functional genomics. Nat Commun. 2014;5:3849.

Zhou YL, Pan YJ, Xie XW, Zhu LH, Xu JL, Wang S, et al. Genetic diversity of rice false smut fungus, Ustilaginoidea virens and its pronounced differentiation of populations in North China. J Phytopathol. 2008:156(9):559-64.

Zhou YL, Xie XW, Zhang F, Wang S, Liu XZ, Zhu LH, et al. Detection of quantitative resistance loci associated with resistance to rice false smut (Ustilaginoidea virens) using introgression lines. Plant Pathol. 2014;63:365-72.

Ready to submit your research? Choose BMC and benefit from:

- fast, convenient online submission

- thorough peer review by experienced researchers in your field

- rapid publication on acceptance

- support for research data, including large and complex data types

- gold Open Access which fosters wider collaboration and increased citations

- maximum visibility for your research: over $100 \mathrm{M}$ website views per year

At $\mathrm{BMC}$, research is always in progress.

Learn more biomedcentral.com/submissions 